\title{
Benefícios da cooperação ambiental inter-organizacional: um estudo exploratório em indústrias metalúrgicas gaúchas
}

\author{
Sidarta Ruthes de Lima \\ sidartaruthes@ gmail.com - Centro Federal de Educação Tecnológica do Paraná - CEFET/PR \\ Igor Bernardi Sonza \\ igorsonza@gmail.com - Universidade Federal do Rio Grande do Sul - UFRGS \\ Paulo Sérgio Ceretta \\ ceretta@smail.ufsm.br - Universidade Federal de Santa Maria - UFSM \\ Antonio Marcos Coelho da Rocha \\ antonio_rocha@pop.com.br - Universidade Federal de Santa Maria - UFSM
}

\begin{abstract}
RESUMO
$\mathrm{O}$ artigo em questão visa evidenciar um modelo de cooperação inter-organizacional para o reaproveitamento de resíduos provindos de indústrias metalúrgicas e realizar um estudo empírico de sua viabilidade em termos de redução de custos para as empresas beneficiadas e diminuição de externalidades ambientais negativas. Para o desenvolvimento da pesquisa foi utilizada uma análise exploratória, onde os dados primários são oriundos das empresas do setor metalúrgico da cidade de Santa Maria/RS, da Usina Gerdau Riograndense (Grande Porto Alegre) e transportadoras da região. Através da simulação realizada, ficou evidenciado que os resíduos do setor metalúrgico podem ser reaproveitados através da parceria empresarial, gerando benefícios econômicos e ambientais, além de proporcionar várias melhorias na qualidade dos processos das empresas metalúrgicas, inclusive na redução dos custos de falhas internas e, consequientemente, na redução dos custos globais da qualidade.
\end{abstract}

Palavras-chave: Gestão Ambiental; Cooperação; Cooperação Ambiental.

\begin{abstract}
The article in question aims at to evidence a model of inter-organizational cooperation for the reuse of residues come from metallurgic industries and to carry through an empirical study of its viability in terms of reduction of costs for the benefited companies and reduction of negative environmental externalities. For the development of the research, an exploratory analysis was used, where the primary data are deriving of the metallurgic sector companies of Santa Maria/RS, of the Gerdau Riograndense Plant (Porto Alegre) and Transport Companies of the region. Through the simulation, was evidenced that the residues of the metallurgic sector can be better used through the enterprise partnership, generating economic and environmental benefits, beyond providing some improvements in the quality of the processes of the metallurgic companies, also in the reduction of the costs of internal imperfections and, consequently, in the reduction of the global costs of the quality.
\end{abstract}

Key words: Environmental management; cooperation; environmental cooperation. 


\section{INTRODUÇÃO}

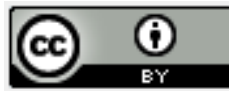

Uma das principais tendências que vêm se intensificando na economia, sob o marco da globalização e do processo de reestruturação industrial, são as formas de relações intra e interorganizacionais, particularmente aquelas envolvendo pequenas e médias empresas. A formação e o desenvolvimento de redes vêm ganhando relevância não só para as economias de vários países industrializados como Itália, Japão e Alemanha, como também para os chamados países emergentes ou de economias em desenvolvimento como México, Chile e o próprio Brasil (Amato Neto 2000).

As pequenas e médias empresas brasileiras estão necessitando, mais do que nunca, investir em projetos inovadores e sustentáveis, tanto do ponto de vista econômico, como social. A concorrência está cada vez mais organizada e os clientes estão mais exigentes. O mercado é muito complexo, as necessidades dos clientes mudam numa velocidade nunca antes percebida; hoje há uma tendência, amanhã não existe mais. É muito difícil administrar nesta atual circunstância.

Hoje, para obter sucesso nos negócios, são necessárias certas capacidades e competências que antigamente não eram usadas. Inovar é fundamental, mas fazer com qualidade o que já está pesquisado e amplamente divulgado também é importante. É preciso desenvolver novas formas de estruturas organizacionais, enxutas e flexíveis, aliando a intuição com a técnica para criar um futuro mais próspero para as empresas de pequeno porte.

Dentro deste contexto, o artigo em questão visa evidenciar um modelo de cooperação inter-organizacional para o reaproveitamento de resíduos provindos de indústrias metalúrgicas e realizar um estudo empírico de sua viabilidade em termos de redução de custos para as empresas beneficiadas e diminuição de externalidades ambientais negativas. Inicialmente, apresenta-se uma revisão da literatura, com referências de publicações a respeito do assunto, 
assim como o parecer de alguns autores a respeito do tema proposto. A seguir, encontra-se explicitado o método aplicado neste estudo, com a caracterização do trabalho e apresentação das informações utilizadas na pesquisa. Por fim, são apresentados os resultados obtidos através do modelo de cooperação ambiental proposto, a conclusão do estudo e recomendações para futuras pesquisas.

\section{MODELOS DE COOPERAÇÃO COMO ESTRATÉGIAS COMPETITIVAS}

Para formular boas estratégias num mercado altamente competitivo como o atual, a análise das variáveis que influenciam e causam algum tipo de impacto nos negócios deve ser muito bem fundamentada. Porter (1986) afirma que existem cinco forças que afetam uma indústria, em que o ponto básico na formulação de uma estratégia de sucesso está nas diferentes habilidades das empresas em lidar com essas forças. As forças que afetam uma indústria são: (i) poder de negociação dos fornecedores; (ii) poder de negociação dos compradores; (iii) ameaça de novos entrantes no mercado; (iv) ameaça de produtos ou serviços substitutos; e, (v) rivalidade entre as empresas existentes na própria indústria. Para evitar ou amenizar essas forças, Porter (1986) destaca que a estratégia de cooperação empresarial pode criar vantagem competitiva através de compras e vendas (conjunta) de insumos e produtos.

Para Filion (2001) um empreendimento cooperativo proporciona um caminho alternativo para a criação e o gerenciamento de uma organização. Podem encorajar grupos de indivíduos e empreendimentos a se juntar em torno de um projeto comum. Pequenas empresas, individualmente, são frágeis para agüentar a competição nos mercados estrangeiros, mas juntas se transformam em fortes competidoras. 
Existe uma dicotomia entre as palavras cooperação e competição, pois literalmente é uma relação incompatível, mas no mundo dos negócios o resultado dessa relação está mudando. Para Lipnack e Stamps (1994), a combinação das palavras cooperação e competição resultam no termo co-opetition. Este termo é resultado de um estilo de organização mais flexível, que utiliza a cooperação para transpor fronteiras, em vez de competir para eliminá-las. São competidores que cooperam entre si e trabalham em conjunto.

Neste contexto, uma forma de cooperação que vem tendo destaque é a aliança estratégica. Aaker (2001) define aliança estratégica como sendo uma colaboração que potencializa as forças de duas ou mais organizações para que alcancem metas estratégicas. $\mathrm{O}$ autor salienta que os resultados da colaboração entre as empresas deveriam ter valor estratégico e contribuir para um empreendimento viável que possa resistir a ataques competitivos e a mudanças de ambiente. As alianças estratégicas são motivadas por um desejo de alcançar benefícios como: (i) gerar economia de escala; (ii) acesso a mercados estratégicos; (iii) superar barreiras comerciais; (iv) completar linhas de produtos; (v) acesso a uma tecnologia; (vi) usar o excesso de capacidade; (vii) fabricação de baixo custo; (viii) ter acesso a um nome ou a uma relação com cliente; e, (ix) reduzir o investimento demandado.

Oliveira (1999) afirma que para se obter uma aliança estratégica, empresas concorrentes precisam alinhar seus objetivos de forma comum, como, por exemplo, aplicar recursos para reduzir os custos e acelerar o retorno do investimento. As atividades ligadas ao acordo de aliança podem ser contratuais ou informais, mas é importante que cada empresa mantenha sua autonomia estratégica. Para Aaker (2001) quanto mais informal o acordo de cooperação, mais rápido e flexível esse pacto pode ser implementado.

De acordo com Lorange e Roos (1996), existem alianças estratégicas com elos verticais através de empresas que complementam os elos ao longo da cadeia produtiva, e elos 
horizontais, através de empresas que oferecem produtos similares. Há, também, o grau de interdependência entre as empresas, que varia da mais alta (fusão e aquisição, participação acionária), a intermediaria (joint venture), até a mais baixa interdependência (cooperação formal e informal). Uma empresa pode desejar começar de maneira menos comprometida e, depois, aumentar o tipo de relacionamento cooperativo no decorrer do tempo.

Lorange e Roos (1996) destacam que, para obter sucesso numa aliança, é preciso que ambas as partes tenham intenções estratégicas que sejam harmonizáveis e explícitas desde o início. A formação de alianças estratégicas bem-sucedidas ocorre como um processo político e analítico gradual, complexo e combinado. Para os autores, é possível classificar as fases do processo de decisão durante a negociação de cooperação, conforme a Figura 1. Segundo Aaker (2001), a chave para o sucesso de uma aliança estratégica está na equilibrada contribuição relativa que cada parceiro oferece ao longo do tempo, pois os dois lados devem obter benefícios.

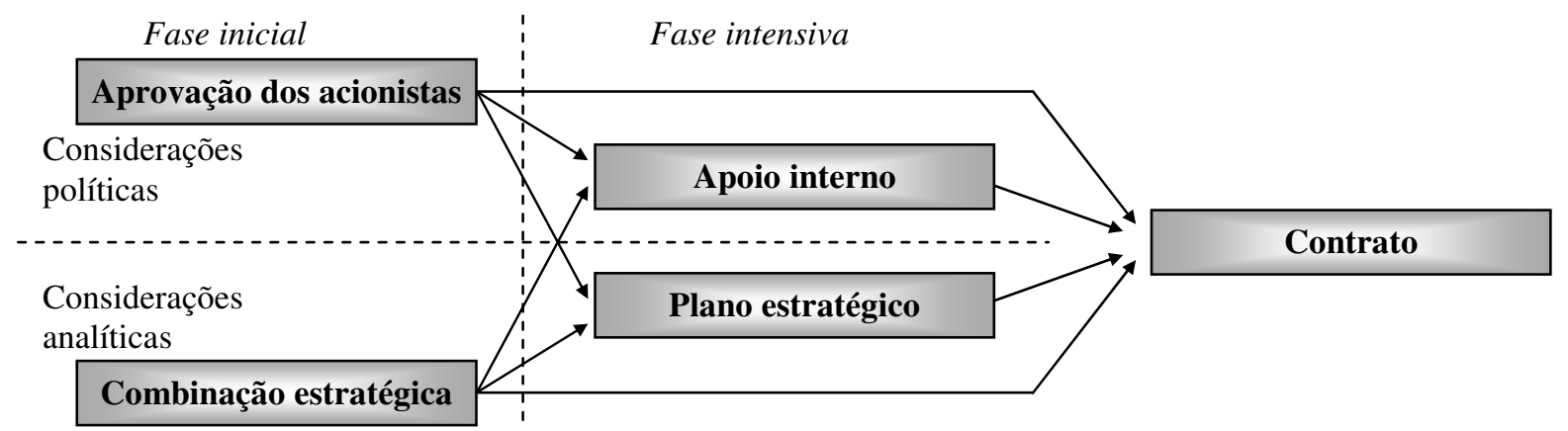

Figura 1- Modelo do processo de formação de uma aliança estratégica

Fonte: Adaptado de LORANGE e ROOS (1996, p. 39).

Após a observação visual da Figura 1, constata-se que o processo de formação de aliança estratégica envolve duas fases: uma inicial e outra intensiva. Durante a fase inicial, as empresas precisam obter a aceitação e apoio dos principais acionistas, tendo o estrategista o papel de indicar uma parceria estratégica clara para as empresas-sócias, tanto nas considerações políticas como nas considerações analíticas. Desta forma, pode-se evoluir para 
a fase intensiva, onde há um total apoio dos sócios e a possibilidade de determinar um plano estratégico comum, com políticas e um estudo analítico do negócio (viabilidade).

Uma forma de aliança muito pesquisada e estudada é a joint venture. Para Gandolfi (1998) joint venture ou merger é uma forma de colaboração entre empresas que possui características como: i) a fusão e/ou associação de capitais; ii) a participação acionária; iii) a transação ou operação conjunta, onde o aporte de capital pode ser um mix de bens tangíveis, bens intangíveis ou bens líquidos.

Outro termo utilizado para definir aliança organizacional e que pode viabilizar várias necessidades das empresas é a cooperação inter-organizacional. Amato Neto (2000) destaca algumas dessas necessidades que podem ser cooperadas, tais como: (i) combinar competências e knowhow; (ii) dividir gastos e compartilhar os benefícios de pesquisas tecnológicas; (iii) compartilhar riscos e custos de explorar novas oportunidades; (iv) oferecer uma linha de produtos diversificados e de qualidade superior; (v) exercer uma pressão maior no mercado com aumento de competitividade em benefício do cliente; (vi) compartilhar recursos; (vii) fortalecer o poder de compra; e, (viii) obter força no mercado internacional.

Segundo Lipnack e Stamps (1994), as combinações inteligentes de pequenas empresas passam a representar vantagens competitivas quando problemas e dificuldades são resolvidos em conjunto. As alianças podem atender a propósitos específicos, como: (i) comprar cooperativamente; (ii) comercialização conjunta; (iii) combinar recursos de P\&D; (iv) treinamento cooperado; e, (v) estabelecimento de programas de qualidade.

Filion (2001) destaca o consórcio como outro modelo de parceria, no qual parceiros juntam forças para formar um empreendimento grupal ou coletivo que não tem características de uma cooperativa. Lorange e Roos (1996) enfatizam que a aliança estratégica do tipo consórcio permite maior flexibilidade para adaptação a novas oportunidades. Na prática, este 
tipo de aliança envolve várias organizações que têm como similaridade a escassez de recursos, e objetivos e metas a alcançar. O consórcio é muito comum em empresas menores para desenvolverem programas de pesquisa.

Outra forma de aliança é a rede de empresas. As redes surgiram para que muitas empresas de pequeno porte se reunissem para realizar algo que não podem fazer isoladamente. Essas organizações desenvolvem relacionamentos por meio de ligações muito espontâneas com poucos níveis hierárquicos. Essas redes possuem características de liderança diversificada, através de proprietários de empresas, entidades que promovem desenvolvimento econômico, e outros órgãos governamentais que fornecem assistência técnica e, às vezes, financiamento (LIPNACK e STAMPS, 1994).

Por outro lado, estendendo-se a uma análise mais ampla (macro), têm-se a associação do tipo cluster e os Arranjos Produtivos Locais - APLs. Cluster é a concentração setorial e geográfica de empresas, ou seja, um grupo de organizações situadas na mesma região que beneficiam produtos similares. Já os APLs são conjuntos de empresas localizadas numa mesma região que possuem como característica uma especialização comum em determina atividade (Amato Neto 2000; Casarotto Filho \& Pires 2001).

\section{GESTÃO AMBIENTAL COMO ESTRATÉGIA COMPETITIVA}

Um dos grandes desafios para a gestão ambiental é criar sociedades sustentáveis (BORN, 2000). A sustentabilidade só é possível através de esforços como educação fundamental, mudanças nos sistemas de transporte, no desenho institucional de organizações, nos padrões de consumo e produção, inovação tecnológica, e, principalmente, pela participação e mobilização de indivíduos e grupos da sociedade nas decisões e ações pertinentes ao ambiente. 


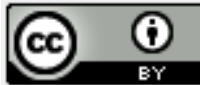

Em se tratando de sinergias entre gestão ambiental e vantagem competitiva para gerar sustentabilidade, foram publicados diversos trabalhos relacionando a este tema (JAFFE et al., 1995; LÓPEZ, 1996; ALBRECHT, 1998; LANOIE E TANGUAY, 1998; NORDSTRÖM E VAUGHAN, 1999; SINCLAIR-DESGAGNÉ, 1999) baseando-se nos pressupostos dos artigos de Porter e Van Der Linde (1995a, 1995b).

Porter (1991) e Porter e Van der Linde (1995b) defendem que a melhoria da performance ambiental é uma potencial fonte de vantagens competitivas, na medida em que poderá resultar em menores custos de produção e de cumprimento da legislação ambiental, bem como originar novas oportunidades de mercado. De acordo com Esty e Porter (1998), as empresas podem ainda conseguir obter as chamadas "vantagens do pioneirismo" pela venda das suas soluções inovadoras a outras empresas.

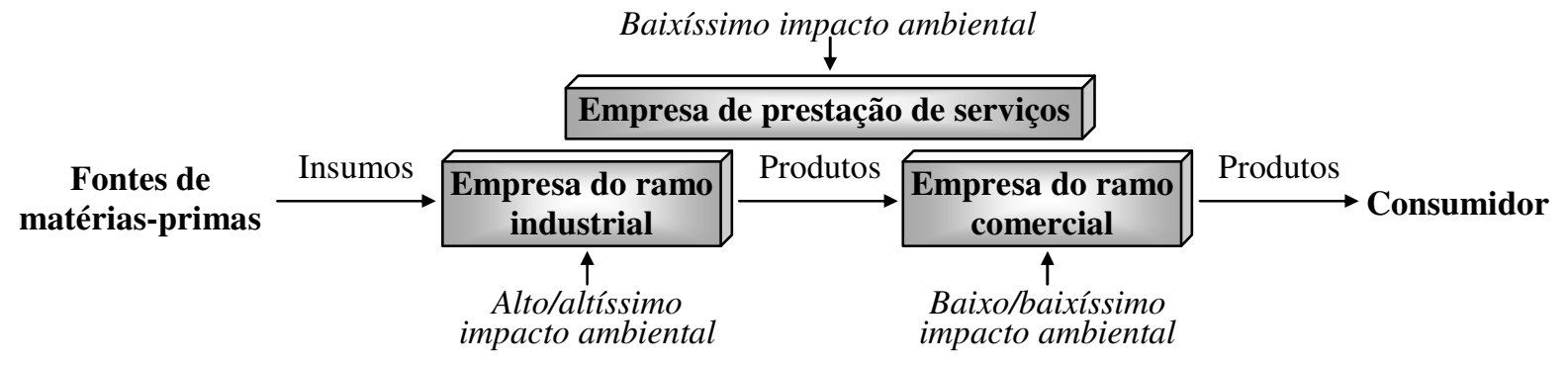

Figura 2 - Setores econômicos e impactos ambientais

Fonte: Adaptado de Andrade et al. (2002).

Existem diversos tipos de impactos ambientais e ecológicos que as organizações causam ao meio ambiente. Andrade et al. (2002) classificam as empresas e seus respectivos impactos ambientais e ecológicos, conforme a Figura 2. As organizações que mais geram impactos ambientais são do ramo industrial, dada por sua característica de serem transformadoras de insumos produtivos em produtos finais. Como as empresas do ramo comercial realizam a intermediação dos bens produzidos pelas companhias industriais, os impactos ambientais são de moderada intensidade. Já as empresas prestadoras de serviço são as que provocam o menor impacto ambiental. Dentro deste contexto, o consumidor final tem 
o papel de agente que induz às mudanças nas organizações, através da conscientização dos efeitos ambientais que as empresas e seus produtos causam no meio ambiente.

Braga et al. (2002), afirmam que o modelo de desenvolvimento utilizado pela sociedade, até atingir seu atual estágio, é representado por um sistema aberto. Este sistema depende de um suprimento contínuo e inesgotável de matéria e energia que, depois de utilizada, é devolvida ao meio ambiente ou simplesmente descartada. Se a premissa de que o Sol é uma fonte inesgotável de energia, podendo fornecer energia a Terra por 5 bilhões de anos, o mesmo não se pode afirmar quanto à matéria, já que sua quantidade é finita. Dentro desta realidade, o meio ambiente possui limites quanto à capacidade de absorver e reciclar matérias e resíduos, tendo a humanidade problemas como elevados níveis de poluição.

Portanto, o próximo estágio é reformular este modelo de desenvolvimento através do conhecimento e técnicas científicas que, em prol da humanidade, possam criar um sistema fechado e sustentável. O modelo de desenvolvimento sustentável proposto por Braga et al. (2002), é um sistema onde todos os materiais e energias oriundos de um processo de produção retornam ou são recuperados através de ações restauradoras que minimizem o impacto ambiental. Este modelo é caracterizado por ser um sistema fechado, onde não há saídas ou devolução de resíduos ao meio ambiente.

A administração de recursos naturais é uma questão muito discutida atualmente na gestão ambiental. Braga et al. (2002) classificam os recursos naturais em dois grupos: (i) recursos renováveis (depois de utilizados ficam disponíveis novamente, devido aos ciclos naturais); e, (ii) recursos não-renováveis (uma vez utilizado, não pode ser aproveitado).

Para a manutenção dos organismos, populações e ecossistemas o controle responsável dos recursos naturais é fundamental. Segundo Margulis (1996b), os recursos renováveis podem tornar-se exauríveis, e os não-renováveis podem ao menos ser considerados não 


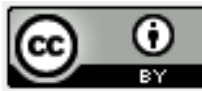

exauríveis. Esta questão dependerá, entre outros fatores, do horizonte de planejamento, do nível de utilização do recurso e dos custos de exploração.

Levando em consideração os riscos inerentes à gestão dos recursos naturais, pode-se afirmar que existem vários estudos realizados sobre a temática do risco em relação à administração ambiental, demonstrando a crescente preocupação que as organizações estão dedicando com esta questão. Lage (2003) destaca o passivo ambiental como fator de risco e o define como sendo alguma deficiência existente nas áreas de segurança, saúde e proteção ambiental, em que a solução pode significar investimentos ou, mesmo, pode impedir a continuidade do negócio.

Figueiredo (2001) salienta a importância da simulação como gerenciamento do risco. A simulação é uma ferramenta gerencial que pode ser utilizada para avaliar as alternativas de projetos, planos e políticas sem a necessidade de experimentações de um sistema real.

No estudo de Ceretta et al. (2003), fica evidenciado que é possível obter benefícios econômicos e ambientais sem investimento ou com valores insignificantes com apenas uma reorganização do processo operacional ou mudança no layout. Muitos empresários acreditam que a implantação de uma gestão ambiental é onerosa e sem retorno significativo, mas com o estudo de Ceretta et al. (2003), foram constatadas várias medidas ambientais, implementadas com criatividade e inovação, que trouxeram grandes reduções nos orçamentos empresariais, comprovando que este paradigma deve ser revisto.

Para Margulis (1996a), as iniciativas relacionadas ao meio ambiente devem ser analisadas segundo a relação custo e benefício, de modo a assegurar a eficácia e a eficiência econômica. O autor destaca que as oportunidades "ganha-ganha" devem ser as primeiras a serem implementadas. Ainda existem muitas situações em que a boa política econômica coincide com a boa política ambiental. 
Conforme Andrade et al. (2002), as empresas do ramo industrial, mais especificamente às organizações metalúrgicas, devem estabelecer estratégias ambientais visando: (i) a eliminação de questões legais com o governo através de estrita observância à legislação vigente; (ii) a redução de dispêndios com insumos produtivos mediante racionalização por meio de seus métodos operacionais; (iii) a criação e aprimoramento de seus processos produtivos, com a eliminação/redução de perdas e geração de resíduos ao longo da cadeia de agregação de valores; (iv) a eliminação, criação e aperfeiçoamento de produtos a serem ofertados no mercado, dentro do contexto ambiental e ecológico; e, (v) a redução ou eliminação de riscos ambientais.

Dentro da lógica da parceria, no Brasil existe a Sociedade para o Incentivo ao Gerenciamento Ambiental (SIGA) que forma grupos de trabalho com finalidade de ajudar as empresas brasileiras a encontrarem meios de usarem resíduos de outras empresas na fabricação de produtos mais favoráveis ao ambiente.

Outra entidade que desenvolve e dissemina um conhecimento vasto na área ambiental é a ISO - International Organization for Standardization (2003). A ISO é uma instituição não-governamental, com sede na Suíça, que desenvolveu um conjunto de diretrizes que especifica, descreve e orienta todo o processo de certificação, auditoria e avaliação do Sistema de Gestão Ambiental. Esse conjunto de diretrizes é denominado pela entidade como "Família ISO 14000”. Essa família de normas compreende duas dimensões: uma ao nível organizacional e outra ao nível de produtos e serviços. No nível organizacional as normas descrevem os seguintes padrões: i) implementação do Sistema de Gestão Ambiental; ii) condução de auditorias e investigações ambientais; e, iii) avaliação da performance ambiental. Quanto ao nível de produtos e serviços as normas descrevem: i) requisitos e declarações 
ambientais; ii) condução da avaliação do ciclo de vida; e, iii) direção dos aspectos ambientais para produtos e sua padronização.

\section{ASPECTOS METODOLÓGICOS}

Para o desenvolvimento deste artigo foi utilizada uma pesquisa exploratória com base na técnica de estudo de campo. Foram coletados dados relativos à geração e controle dos resíduos renováveis do setor metalúrgico para, posteriormente, desenvolver um modelo de aliança para pequenas e médias empresas que possibilite a otimização de um investimento nos moldes de uma cooperação ambiental.

Segundo Gil (2002), o fim da pesquisa exploratória é proporcionar maior familiaridade com o problema, com vistas a torná-lo mais explícito ou a construir hipóteses no sentido de aprimorar idéias ou descobrir intuições. Foram usados para este fim, dados primários extraídos junto a uma siderúrgica, três pontos de coleta de resíduos metálicos na cidade de Santa Maria/RS, três transportadoras da região e 12 empresas metalúrgicas; e, dados secundários extraídos da internet, documentos públicos e pesquisa bibliográfica. Os dados primários foram obtidos através dos seguintes instrumentos de pesquisa: (i) questionários padronizados; e, (ii) entrevistas semi-estruturadas. A amostra utilizada é não-probabilística intencional. Segundo Marconi e Lakatos (2002), este tipo de técnica de amostragem não faz uso de formas aleatórias de seleção.

A siderúrgica escolhida para este estudo foi Gerdau S.A. que está localizada na cidade de Porto Alegre/RS. Fontes da própria companhia afirmam que o Grupo é líder em reciclagem de ferro e aço na América Latina, com reaproveitamento de mais de 2 milhões de toneladas por ano no Brasil. Possui 18 centros de compra de sucata, mais especificamente, 10 usinas e 8 pontos de recolhimento de sucata de aço no país. A Gerdau foi escolhida para a simulação 
deste estudo porque possui como característica a política de atuar diretamente na compra de sucata nas indústrias metalúrgicas.

No tratamento dos dados foram utilizadas as seguintes técnicas: (i) seleção (exame minucioso e crítico dos dados); (ii) codificação (classificação); e, (iii) tabulação através de planilhas de cálculos (construção de tabelas, gráficos, fluxogramas e figuras). Para a análise dos dados foram utilizadas técnicas de interpretação e explicação. Desta forma, foi possível partir de dados puros para construção de informações.

Para determinar o modelo de cooperação ambiental foram utilizadas as técnicas de indução e dedução científica. De acordo com Cervo e Bervian (2002), a indução e dedução são processos que se complementam e que são utilizados para demonstrar a verdade das proposições submetidas à análise. Por isso, a indução reforça-se pelos argumentos dedutivos. Através da indução científica pode ser possível chegar à conclusão de alguns casos observados a partir da espécie que os compreende e a lei geral que os rege. Já a técnica da dedução consiste em construir estruturas lógicas com a relação entre antecedente e conseqüente, entre premissa e conclusão.

\section{MODELO DE COOPERAÇÃO AMBIENTAL: UM ESTUDO EXPLORATÓRIO}

As pequenas e médias empresas metalúrgicas precisam de uma administração enxuta para poder competir num futuro cada vez mais complexo. Neste setor existem grandes companhias com disponibilidade de captação de recursos e tecnologias que estão além da realidade das pequenas e médias empresas.

Muitas dessas grandes metalúrgicas possuem baixo custo de produção com alto padrão de qualidade, através dos altos níveis de produção e, conseqüentemente, da economia de escala. É necessário, às pequenas e médias empresas, um diferencial competitivo capaz de 
captar uma fatia de mercado que mantenham suas estruturas corporativas, garantindo, assim, a sobrevivência e crescimento. A cooperação empresarial do setor metalúrgico, mais precisamente no aspecto ambiental, é uma estratégia que pode reduzir os custos operacionais, influenciando diretamente no resultado final de cada organização.

Na indústria metalúrgica há uma percentagem considerável de matéria-prima que não é aproveitada devido a diversos fatores, os mais comuns são: (i) desperdício devido à disposição do material no estoque (chapa amassada, arranhões, ferrugem, barras e vigas tortas); (ii) erro de projeto, inviabilizando o material; (iii) erro de execução ou de processo, devido à falta de máquinas adequadas e treinamento de pessoal; (iv) sobras e retalhos de chapas e barras que não podem ser aproveitados (resultado normal do processo produtivo); (v) operação de estampa, solda, furo, corte e fresa que produzem resíduos metálicos - conhecidos no meio metal-mecânico como cavacos, rebarbas, tiras, pó metálico, etc; e, (vi) resíduos de material de apoio utilizado no processo de fabricação (pinos de rebites, eletrodos de solda, disco de corte, disco de desbaste, brocas, serras, latas de produtos de acabamento e etc).

Existem no mercado diversas empresas que coletam aço para reciclagem. São popularmente conhecidas como "ferros velhos" - depósitos de resíduos. Essas empresas fazem o papel de intermediários entre a indústria metalúrgica e a indústria siderúrgica. Os depósitos de reciclagem realizam o processo de coleta, separação e transporte dos resíduos metálicos (sucatas) até as instalações das siderúrgicas, recebendo por este serviço um pagamento em dinheiro ou em produtos siderúrgicos, como barras, vigas e chapas metálicas para revender.

Na cooperação ambiental entre as empresas metalúrgicas, os resíduos, provindos do processo produtivo, podem ser coletados e transportados até as siderúrgicas, eliminando, assim, o intermediário. Desta forma, as metalúrgicas podem diminuir os gastos referentes a esses resíduos, através de uma melhor remuneração paga pela siderúrgica. A grande 
dificuldade deste modelo está relacionada com a quantidade ideal de resíduos que viabilize a logística do negócio. Individualmente, as metalúrgicas de pequeno e médio porte têm dificuldades para obterem uma quantidade de resíduos que viabilizem o processo do negócio.

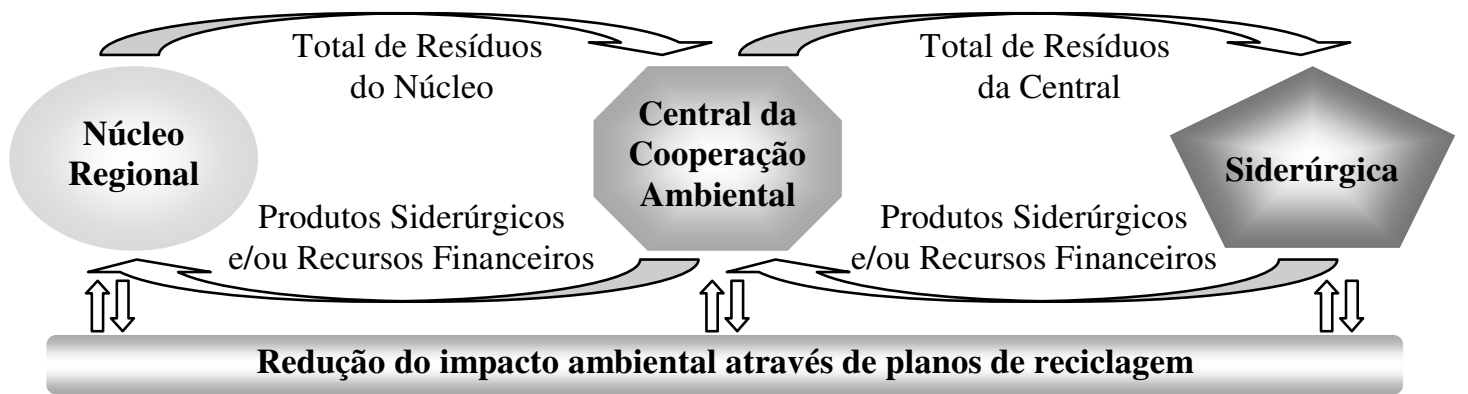

Figura 3 - Modelo de cooperação ambiental para pequenas e médias empresas metalúrgicas Fonte: Desenvolvido pelos autores

A proposta de um modelo de cooperação ambiental é composta por três interfaces: (i) núcleo regional; (ii) central da cooperação ambiental; e, (iii) siderúrgica. Essa cooperação deve funcionar como um sistema fechado, o mesmo proposto por Braga et al. (2002), com inter-relações entre o núcleo regional, a central da cooperação ambiental e a siderúrgica, através da reciclagem e preservação do meio ambiente, conforme a

Figura 3.

O núcleo regional deve ser composto por empresas metalúrgicas que possuem em comum a utilização do mesmo tipo de matéria-prima utilizada no processo produtivo da siderúrgica. Além disto, o núcleo regional deve abranger uma área geográfica comum às empresas, conforme a proximidade e facilidade de tráfego. Portanto, uma cidade ou região pode ser dividida em vários núcleos, tendo como critério a minimização dos custos de transporte até a central de cooperação ambiental, conforme a Figura 4. Desta forma, regiões como bairros, distritos, e cidades menores podem formar um núcleo, desde que possuam a proximidade como característica comum.

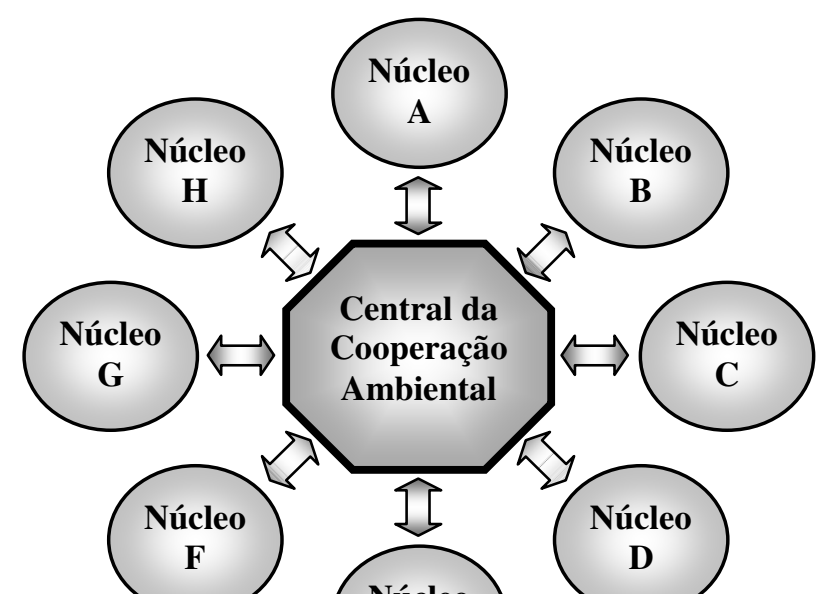


Figura 4 - Vários núcleos formando uma cooperação ambiental para o setor metalúrgico Fonte: Desenvolvido pelos autores

A central da cooperação ambiental deve ser responsável pela logística do processo de reciclagem, com atribuições de tarefas como determinação dos custos do negócio, a negociação com a siderúrgica, a contratação de transporte, a coleta do material, a criação de seminários e reuniões relacionadas com as questões estratégicas e operacionais.

A siderúrgica fornece à central da cooperação ambiental as especificações do material que utiliza no seu processo produtivo, bem como a quantidade mínima de material reciclado, o preço pago pela tonelada de resíduos de aço, o prazo de pagamento, a possibilidade de pagamento em produtos da própria siderúrgica, o método de coleta, separação e transporte do material e demais tarefas operacionais. A Gerdau possui uma área de "engenharia de sucata" preparada para atender seus fornecedores.

Uma das vantagens que essa cooperação pode proporcionar para os parceiros diz respeito ao pagamento da sucata na forma de produtos da própria siderúrgica. Desta forma, os cooperados podem reduzir o transporte, pois o caminhão que leva a sucata pode trazer a matéria-prima para a central distribuir entre os filiados. Outra vantagem que pode ser concretizada com a cooperação empresarial se refere às compras de matérias-primas diretamente do fabricante.

A parceria com outras empresas possibilita reunir uma quantidade ótima de compra de materiais (Lote Econômico de Compras - LEC) e, desta forma, seria possível reduzir os custos 
de produção através de preços mais atraentes e, como conseqüência, o aumento da margem de contribuição entre custo e preço de venda, tornando-se mais competitivo no mercado. Individualmente seria muito difícil conseguir comprar diretamente da siderúrgica, pois seria complicado atingir o LEC que otimizasse esta negociação.

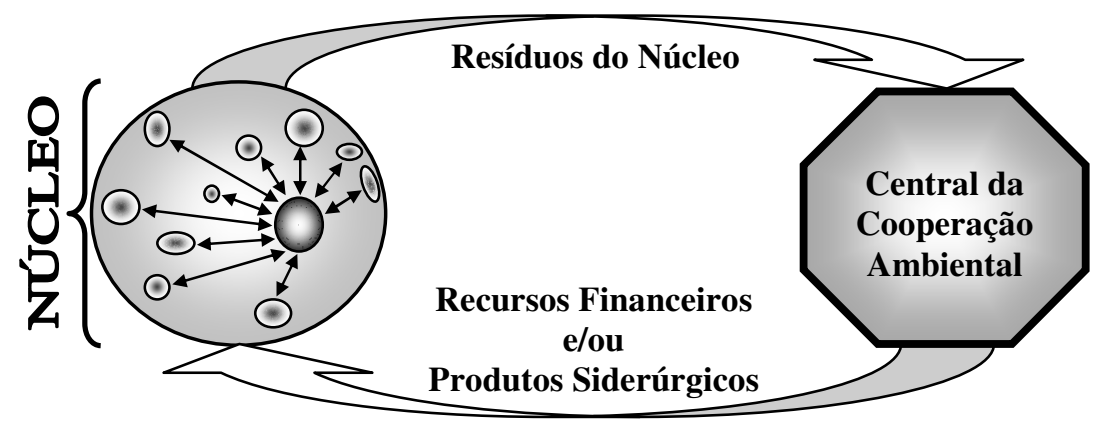

Figura 5 - Formação de um núcleo e escolha da empresa responsável pela coleta e estoque Fonte: Desenvolvido pelos autores

Para viabilizar a cooperação, os núcleos precisam estar organizados de forma a otimizar todas as tarefas relacionadas com a separação, coleta e transporte do material reciclável. Para este modelo de cooperação é necessário que uma empresa tenha a tarefa de armazenar todo o material reciclável do núcleo para reduzir os custos de transporte, facilitando a coleta da central da cooperação ambiental, conforme a Figura 5.

Esse armazenamento deve ser temporário e sua duração coincidir com o Lote Econômico do Núcleo (LEN). É fundamental que a empresa escolhida para ser responsável pelo núcleo tenha uma balança para pesar e controlar a quantidade (kg) de ferro e aço. Para escolher a empresa que deve ser responsável pela armazenagem são necessários alguns critérios que viabilize o núcleo. Para o propósito deste estudo foram estimados os seguintes critérios: (i) possuir uma área (m2) que atenda o estoque temporário de resíduos; (ii) localização que facilite o transporte, de forma a minimizar os custos; (iii) possuir uma área 


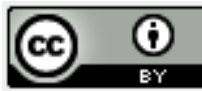

destinada aos produtos siderúrgicos que são absorvidos como forma de pagamento efetuado pela siderúrgica; e, (iv) estrutura administrativa e operacional. Deve-se levar em consideração que as sucatas metálicas a serem armazenas comumente estão contaminadas por óleos, passando a serem classificadas como resíduos perigosos (Resíduos Classe I) pela Resolução CONAMA 23 de 12/12/1996, sendo, então, passível de armazenamento segundo NBR12235/87 (resíduos classe I).

A central de cooperação ambiental poderia ser qualquer empresa estruturada para executar todas as fases do projeto, mas além deste quesito, o ideal seria a utilização de uma empresa responsável por um núcleo. Desta forma, pode-se reduzir despesas através do uso da mesma estrutura administrativa reservada ao núcleo, ou seja, um núcleo seria, também, responsável pela central da cooperação ambiental. A Tabela 1 contém os dados relativos à negociação de venda dos resíduos de aço. Uma coluna contém informações relativas à venda de sucata diretamente à siderúrgica e outra com dados de negociação com os intermediários.

Os dados de negociação (condições de vendas) foram coletados junto à empresa Gerdau S.A. (siderúrgica) e organizações coletoras de ferro e aço (intermediários) de Santa Maria.

Tabela 1 - Negociação individual através de intermediários versus a cooperação ambiental

\begin{tabular}{l|r|r}
\multicolumn{1}{c|}{ Descrição dos Dados $^{1}$} & $\begin{array}{c}\text { Negociação com os } \\
\text { Intermediários }\end{array}$ & $\begin{array}{c}\text { Negociação direta } \\
\text { com a Siderúrgica }\end{array}$ \\
\hline Preço pago pela sucata (kg) & 0,08 & 0,28 \\
Quantidade mínima para abrir negociação $(\mathrm{kg})$ & Sem restrição & Sem restrição \\
Pagamento em material (Sim ou Não) & A combinar & Sim \\
Prazo para pagamento em R $\$$ & À vista & A vista \\
Prazo para pagamento em material (perfis e chapas de aço) & 21 dias & 21 dias \\
\hline
\end{tabular}

Nota: ${ }^{1}$ Dados coletados junto aos intermediários (ferro velhos) de Santa Maria e a Siderúrgica Gerdau S.A. de Porto Alegre/ Sapucaia do Sul.

Fonte: Desenvolvido pelos autores

Além do mais, foram coletadas algumas informações relativas aos resíduos das empresas metalúrgicas para estabelecer uma estimativa do trabalho individual na venda de resíduos, bem como numa atuação cooperada (cooperação ambiental), conforme a Tabela 2 . O 


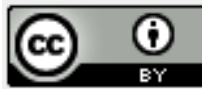

lote econômico é a quantidade mínima de resíduos de aço que uma única empresa precisa para não ter prejuízo com os gastos de coleta, transporte e venda dos respectivos resíduos.

Tabela 2 - Estimativa das informações: negociação individual versus cooperação ambiental

\begin{tabular}{|c|c|c|c|}
\hline Estimativa dos dados & $\begin{array}{c}\text { Empresa } \\
\text { Individual }\end{array}$ & Núcleo $^{3}$ & $\begin{array}{c}\text { Central da Cooperação } \\
\text { Ambiental } \\
\end{array}$ \\
\hline Quantidade - lote de venda de resíduos (kg) & 1.000 & 10.000 & 100.000 \\
\hline Número de empresas cooperadas & 1 & 10 & 100 \\
\hline Custo da mão-de-obra (hora) ${ }^{1}$ & 4,23 & 4,23 & 4,23 \\
\hline Índice de produtividade $(\mathrm{kg} / \mathrm{hora})$ & 1.000 & 1.000 & 1.000 \\
\hline Capacidade máxima de transporte $(\mathrm{kg})$ & 4.000 & 35.000 & 35.000 \\
\hline Número de transportes & 1 & 1 & 3 \\
\hline Preço do transporte para siderúrgica $(\mathrm{R} \$)^{2}$ & 375,00 & 0,00 & 0,00 \\
\hline Preço do transporte para o intermediário $(\mathrm{R} \$)$ & 50,00 & 0,00 & 0,00 \\
\hline Indicador de sucata de ferro e aço/empresa $(\mathrm{kg})$ & 1.000 & 1.000 & 1.000 \\
\hline
\end{tabular}

Nota: ${ }^{1}$ Piso salarial metalúrgico estimado de acordo com dados da SINMETAL (2004).

Nota: ${ }^{2}$ Para 35 toneladas de sucata de aço a Gerdau paga o frete de Santa Maria a Porto Alegre.

Nota: ${ }^{3}$ Os custos do frete referente ao recolhimento da sucata de todos os Núcleos estão embutidos no frete

Fonte: Desenvolvido pelos autores

Para esta cooperação ambiental foram considerados 10 núcleos regionais e cada núcleo tem 10 empresas metalúrgicas, um total de 100 empresas. Para determinar os custos de transporte foram realizados três orçamentos para os seguintes casos: (i) transporte na região de Santa Maria (da metalúrgica até o ponto de coleta de resíduos - depósito de reciclagem); (ii) transporte de Santa Maria para Porto Alegre (capacidade de transporte $4.000 \mathrm{~kg}$ ); e, (iii) transporte de Santa Maria para Porto Alegre (capacidade $35.000 \mathrm{~kg}$ ).

Para realizar a simulação da negociação individual e da cooperação entre empresas metalúrgicas, foram consideradas quatro situações de transação comercial dos resíduos: (i) negociação individual com o intermediário; (ii) negociação individual com a siderúrgica; (iii) negociação entre a cooperação de empresas e a siderúrgica, com pagamento dos resíduos mediante recursos financeiros; e, (iv) negociação entre a cooperação de empresas e a siderúrgica, com pagamento dos resíduos mediante aquisição de matéria-prima (produtos da siderúrgica). Além das situações descritas anteriormente, foram demonstrados os benefícios da cooperação ambiental versus negociação individual, conforme a Tabela 3. 
Tabela 3 - Simulação financeira da negociação individual e cooperação ambiental

\begin{tabular}{|c|c|c|c|c|c|c|c|}
\hline \multirow{2}{*}{ Demonstração do Resultado } & \multicolumn{2}{|c|}{$\begin{array}{c}\text { Negociação } \\
\text { Individual }\end{array}$} & \multicolumn{2}{|c|}{$\begin{array}{c}\text { Cooperação } \\
\text { Ambiental }\end{array}$} & \multicolumn{3}{|c|}{ Benefícios da Cooperação } \\
\hline & (1) & (2) & (3) & (4) & $(3-1)$ & $(3-2)$ & $(4-2)$ \\
\hline 1. Receita & 80,00 & 280,00 & $28.000,00$ & $28.000,0$ & $27.920,0$ & $27.720,00$ & $27.720,0$ \\
\hline 2. Impostos & 0,00 & 0,00 & 0,00 & 0,00 & 0,00 & 0,00 & 0,00 \\
\hline \multicolumn{8}{|l|}{ 3. Custos Operacionais } \\
\hline 3.1. Transporte & 50,00 & 375,00 & 0,00 & 0,00 & $-50,00$ & $-375,00$ & $-375,00$ \\
\hline 3.2. Mão-de-obra Direta & 4,23 & 4,23 & 423,00 & 423,00 & 418,77 & 418,77 & 418,77 \\
\hline \multicolumn{8}{|l|}{ 4. Despesas Operacionais } \\
\hline 4.4. Despesas com Vendas & 15,00 & 15,00 & 15,00 & 15,00 & 0,00 & 0,00 & 0,00 \\
\hline 4.2. Despesas Financeiras & 0,00 & 0,00 & 0,00 & 0,00 & 0,00 & 0,00 & 0,00 \\
\hline 4.3. Despesas Gerais e Administrativas & 10,00 & 10,00 & 100,00 & 100,00 & 90,00 & 90,00 & 90,00 \\
\hline 5. Outras Receitas Operacionais & 0,00 & 0,00 & 0,00 & $9.469,66$ & 0,00 & 0,00 & $9.469,66$ \\
\hline 6. Receitas Financeiras & 0,00 & 0,00 & 0,00 & 0,00 & 0,00 & 0,00 & 0,00 \\
\hline 7. Lucro Operacional & 0,77 & $-124,23$ & $27.462,00$ & $36.931,6$ & $27.461,2$ & $27.586,23$ & $37.055,8$ \\
\hline 8. Receitas Não-Operacionais & 0,00 & 0,00 & 0,00 & 0,00 & 0,00 & 0,00 & 0,00 \\
\hline 9. Despesas Não-Operacionais & 0,00 & 0,00 & 0,00 & 0,00 & 0,00 & 0,00 & 0,00 \\
\hline 10. LAIR (IR = 25\%) & 0,77 & $-124,23$ & $27.462,00$ & $36.931,6$ & $27.461,2$ & $27.586,23$ & $37.055,8$ \\
\hline 11. Resultado Após o IR & 0,77 & $-124,23$ & $27.462,00$ & $36.931,6$ & $27.461,2$ & $27.586,23$ & $37.055,8$ \\
\hline 12. Participação por empresa & 0,77 & $-124,23$ & 274,62 & 369,32 & 273,85 & 398,85 & 493,55 \\
\hline
\end{tabular}

Legenda: (1) Negociação do aço com intermediários; (2) Negociação do aço com a siderúrgica; (3) Pagamento realizado através de dinheiro; (4) Pagamento realizado através de matéria-prima (aço);

Fonte: Desenvolvido pelos autores

Através da observação da Tabela 3, é possível verificar que no lote de $1000 \mathrm{~kg}$ de resíduos, as empresas que atuarem de forma individual e venderem seus resíduos para intermediários, terão uma receita de $\mathrm{R} \$ 0,77$. Mesmo com o valor mais elevado na venda desses resíduos para a siderúrgica, a empresa terá uma perda de $\mathrm{R} \$ 124,23$; fato este devido aos custos de transportes, pois a siderúrgica não paga o frete para uma carga pequena.

Por outro lado, se essas empresas trabalharem de forma cooperada, numa aliança com outras metalúrgicas, poderão se beneficiar de vários fatores que uma rede pode proporcionar. $\mathrm{Na}$ venda do mesmo lote (1000 kg por empresa) de resíduos de aço para a siderúrgica, as metalúrgicas poderiam obter um ganho de $\mathrm{R} \$ 274,62$, pois os custos fixos estariam divididos e o transporte seria por conta da siderúrgica (lote viável para a siderúrgica). Caso a rede aceite negociar esse lote de resíduos por matéria-prima (produto da siderúrgica), os ganhos econômicos poderiam ser ainda maiores, atingindo $\mathrm{R}$ \$ 369,32 por empresa. 
Quando confrontados os resultados entre a negociação individual e a negociação através da cooperação, essa discrepância fica ainda maior, conforme a Tabela 3 (coluna "Benefícios da Cooperação"). As empresas estão deixando de ganhar com a cooperação ambiental. Nesta simulação fica evidente que a cada lote de $1000 \mathrm{~kg}$ de aço, cada organização deixa de arrecadar, no mínimo, $\mathrm{R} \$ 273,85$; podendo atingir até 493,55 reais. Sem contabilizar outros fatores que podem ser promovidos como, por exemplo, os aspectos ambientais.

É possível relacionar dois fatores que influenciam diretamente no desempenho econômico/financeiro do processo de reciclagem dos resíduos das empresas metalúrgicas. $\mathrm{O}$ primeiro fator é a localização da metalúrgica, ou seja, a distância da mesma até o ponto de recolhimento dos resíduos. O segundo é a quantidade mínima necessária para atingir o lote econômico ambiental, ou seja, a quantidade em quilos $(\mathrm{kg})$ que é necessário para não ter prejuízo com encaminhamento dos resíduos à reciclagem. É importante que cada empresa tenha o conhecimento do seu lote econômico ambiental, pois à medida que a quantidade de resíduos varia o resultado é alterado, conforme a Tabela 4 e a Figura 6.

Analisando-se os valores na Tabela 4 e a Figura 6, pode-se perceber que há uma quantidade que representa um ponto de equilíbrio entre a negociação individual com intermediários e a negociação individual com a siderúrgica, pois a partir deste ponto a transação direta com a siderúrgica produz os melhores resultados, isto é devido ao lote de venda de resíduos ter atingido a quantidade ótima para arcar com as despesas de comercialização.

Tabela 4 - Evolução financeira conforme a quantidade de resíduos de ferro e aço

\begin{tabular}{c|rrrr}
\hline \multirow{2}{*}{$\begin{array}{c}\text { Lote de venda } \\
(\mathbf{k g})\end{array}$} & \multicolumn{2}{|c|}{ Negociação Individual } & \multicolumn{2}{c}{ Cooperação Ambiental } \\
\cline { 2 - 5 } & Com Intermediários & Com a Siderúrgica & Pagamento em R\$ & Pagamento com MP \\
\hline 0250 & $-56,06$ & $-331,06$ & 61,17 \\
0500 & $-37,12$ & $-262,12$ & 13,79 & 183,89 \\
0750 & $-18,17$ & $-193,17$ & 136,74 & 276,60 \\
1000 & 0,77 & $-124,23$ & 205,68 & 369,32 \\
1250 & 19,71 & $-55,29$ & 274,62 & 462,03 \\
1500 & 38,66 & 13,66 & 343,56 & 554,75 \\
\hline
\end{tabular}




\begin{tabular}{|c|c|c|c|c|}
\hline & & & & (i) \\
\hline 1750 & $\begin{array}{l}57,60 \\
\end{array}$ & 82,60 & 481,45 & $\overline{647,46}$ \\
\hline 2000 & 76,54 & 151,54 & 550,39 & 740,18 \\
\hline 2250 & 95,48 & 220,48 & 619,33 & 832,90 \\
\hline 2500 & 114,43 & 289,43 & 688,28 & 925,61 \\
\hline
\end{tabular}

Fonte: Desenvolvido pelos autores

Na Figura 6, o ponto de intersecção representa o lote em que a negociação com o intermediário não é mais viável, e a negociação com a siderúrgica começa a ficar mais atraente do ponto de vista econômico. Já a comparação entre a cooperação ambiental com "pagamento em dinheiro" e com "pagamento em matéria-prima" (linhas pontilhadas), é possível notar a diferença do ângulo que existe entre as retas. Na cooperação com "pagamento em MP” existe uma variação maior na medida em que o lote aumenta.
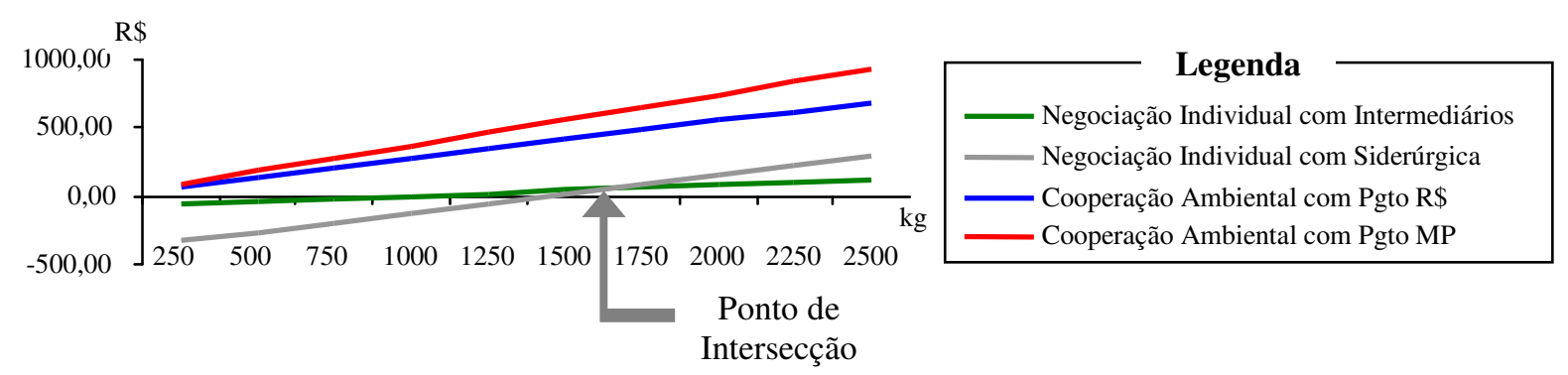

Figura 6 - Quantidade reciclável versus o tipo de negociação

Fonte: Desenvolvido pelos autores

Uma proposta interessante que poderia agregar o negócio individual das empresas que constituem a cooperação seria a reunião do plano de cooperação ambiental com um plano de cooperação de compra de matéria-prima. A reunião desses dois planos (cooperação ambiental e cooperação de compra de matéria-prima) pode ser efetivada através da utilização dos recursos financeiros provindos da própria cooperação ambiental na compra direta de matériaprima (aço). Desta forma, as pequenas e médias empresas podem reduzir o poder de negociação do fornecedor (siderúrgica).

Há outros benefícios que podem ser estimados com a parceria ambiental. Por exemplo, pode ser criado um sistema de informação de estoques de resíduos que otimize o uso de certas 


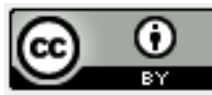

sobras de aço, através do encaminhamento desse material para outra empresa cooperada. Geralmente, os perfis e chapas de aço são comercializados num tamanho padrão.

Esta padronização traz consequiências negativas nos custos de produção, pois geralmente sobram muitos retalhos e pedaços que não podem ser utilizados na fabricação, mas que não deixa de ter um valor significativo, pois pode ser aproveitado melhor no processo produtivo de outra empresa.

Através dos dados relativos aos perfis e chapas de aço que sobram no processo de fabricação (quantidade, bitola, tamanho) é possível criar um método que integre os dados dos resíduos de todas as empresas cooperadas, com facilidade de acesso e comunicação. Desta forma, pode-se reduzir o desperdício com a utilização do material que seria vendido para reciclagem, além de diminuir os custos e melhorar o resultado. Os benefícios são recíprocos, pois ambas as empresas ganham com essa informação, tanto a detentora do resíduo, através da venda dos resíduos por um preço melhor que a reciclagem, como a empresa que utilizará o resíduo como matéria-prima, através da compra da mesma por um preço mais baixo.

\section{CONSIDERAÇÕES FINAIS}

As pequenas e médias empresas podem obter vários benefícios através da aliança organizacional. Formar parcerias empresariais é uma estratégia que pode proporcionar uma vantagem competitiva no mercado, claro se for bem elaborada e efetivada, pois existem estudos que relatam casos de fracassos e que pode servir de subsídio como exemplo de gestão que deve ser evitada.

O modelo proposto de cooperação ambiental evidenciou que várias ações podem ser realizadas em conjunto com outras empresas, onde a discussão principal não é eliminar perdas, mas sim gerenciá-las, sendo possível estimar alguns benefícios, como, por exemplo: 
(i) redução do custo da qualidade; (ii) aumento no resultado final da empresa; (iii) melhorias de gestão dos materiais; (iv) troca de informações; (v) difusão das melhores práticas de gestão da produção; (vi) aumento da qualidade; e, (vii) preservação do meio ambiente. Existem, também, os benefícios intangíveis ou de difícil mensuração que podem ser estimados e relacionados com a estratégia de cooperação ambiental como, por exemplo: (i) melhoria da imagem no mercado; (ii) maior relacionamento com fornecedor de ferro e aço (siderúrgica); (iii) responsabilidade social e ética nos aspectos ambientais das empresas cooperadas; e, (iv) maior comprometimento dos funcionários, pois participam desta política de preservação.

Atuando de forma individual, uma pequena empresa metalúrgica, normalmente, precisa "pagar" para dar um destino responsável aos resíduos metálicos, pois praticamente não há retorno neste tipo de transação. No caso de uma cooperação ambiental, em que há uma parceria com outras empresas em prol de um objetivo comum, os resíduos metálicos podem ter o mesmo destino ambientalmente correto, mas com um benefício econômico/financeiro para todos os participantes da cooperação.

Como recomendação para futuras pesquisas, sugere-se a ampliação da análise para outras atividades de uma empresa metalúrgica. É possível estender a parceria para as mais diversas áreas administrativas como, por exemplo, uma cooperação de compras utilizando o mesmo transporte dos resíduos para compra de matérias-primas, uma parceria para difusão da informação sobre os resíduos, uma cooperação de treinamento da mão-de-obra, bem como no desenvolvimento de produtos.

Neste caso, quanto maior o grau de envolvimento da parceria empresarial, nos mais diversos aspectos que envolvem uma empresa, maior a possibilidade de aumentar os benefícios operacionais e estratégicos, pois o princípio da cooperação é simples: é possível 
aumentar os benefícios individuais de cada empresa se forem diluídas as dificuldades entre os participantes de uma cooperação.

\section{REFERENCIAS BIBLIOGRÁFICAS}

AAKER, D. A. Administração estratégica de mercado. 5. ed. Porto Alegre: Bookman, 2001.

ALBRECHT, J. Environmental Regulation, Comparative Advantage and the Porter Hypothesis. Nota di lavoro. Milão: Fondazione Eni Enrico Mattei, 1998.

AMATO NETO. J. Redes de cooperação produtiva e clusters regionais: oportunidades para as pequenas e médias empresas. São Paulo: Atlas e Fundação Vanzolini, 2000.

ANDRADE, R. O. B.; TACHIZAWA, T.; CARVALHO, A. B. Gestão Ambiental: enfoque estratégico aplicado ao desenvolvimento sustentável. 2. ed. São Paulo: Pearson Education Makrons Books, 2002.

BRAGA, B. et al. Introdução à engenharia ambiental. São Paulo: Prentice Hall, 2002.

BORN, R. H. Grandes desafios para a gestão ambiental. Boletim Fundação Vanzolini, São Paulo, ano 9, n. 42, p. 5, mar./abr. 2000.

CASAROTTO FILHO, N.; PIRES, L. H. Redes de pequenas e médias empresas e desenvolvimento local: estratégias para a conquista da competitividade global com base na experiência italiana. 2. ed. São Paulo: Atlas, 2001.

CERETTA, P. S.; ROCHA, A. M. C.; SONZA, I. B.; LIMA, S. R. Responsabilidade social: gestão ambiental pode gerar lucro. In: III Congresso USP Controladoria e Contabilidade, São Paulo, 2003.

CERVO, A. L.; BERVIAN, P. A. Metodologia científica. 5. ed. São Paulo: Prentice Hall, 2002.

ESTY, D. E; PORTER, M. Industrial Ecology and Competitiveness: strategic implications for the firm. Journal of Industrial Ecology, v.2, n. 1, p. 35-43, 1998.

FIGUEIREDO, L. H. M. Sistema flexível e eficaz para o gerenciamento e a tomada de decisão baseados no risco. Gerenciamento Ambiental. São Paulo, v. 3, n. 16, p. 47-49, set./out. 2001

FILION, L. J. Carreiras empreendedoras do futuro. Revista Sebrae, Brasília, v. 1., p.35-51, out./dez. 2001.

GANDOLFI, C. G. Joint venture: noções práticas para parcerias internacionais. Porto Alegre: FIERGS, 1998. 
GIL, A. C. Como elaborar projetos de pesquisa. 4. Ed. São Paulo: Atlas, 2002.

ISO - INTERNATIONAL ORGANIZATION FOR STANDARDIZATION. Environmental management - The ISO 14000 family of international standards. Disponível em: <www.iso.org >. Acesso em: 16 mai. 2003.

JAFFE, A. B. et al. Environmental regulation and the competitiveness of U.S. manufacturing: what does the evidence tell us?. Journal of Economic Literature, v. XXXIII, p. 132-163, 1995.

LAGE, H. Passivo ambiental. Meio ambiente industrial. São Paulo, v. 7, n. 41, p. 32-34, jan./fev. 2003.

LANOIE, P.; TANGUAY, G. A. Dix exemples de rentabilité financière liés à une saine gestion environnementale. Série scientifique 98S-05, Centre interuniversitaire de recherche en analyse des organisations (CIRANO), Montreal, 1998.

LIPNACK, J.; STAMPS, J. Rede de informações. São Paulo: Makron Books, 1994.

LÓPEZ, A. Competitividad, innovacion y desarrollo sustentable: una discusión conceptual. DT 22, Buenos Aires:CENIT, 1996.

LORANGE, P.; ROOS, J. Aliança estratégica: formação, implementação e evolução. São Paulo: Atlas, 1996.

MARCONI, M. A.; LAKATOS, E. M. Técnicas de pesquisa: planejamento e execução de pesquisas, elaboração, análise e interpretação de dados. 5. ed. São Paulo: Atlas, 2002.

MARGULIS, S. A regulamentação ambiental: instrumentos e implementação. Rio de Janeiro: IPEA; Brasília, IPEA,1996a.

. Meio ambiente: aspectos técnicos e econômicos. Brasília: IPEA, $1996 \mathrm{~b}$.

NORDSTRÖM, H.; VAUGHAN, S. Special Studies 2: Trade and Environment. Geneva: World Trade Organization Publications, 1999.

OLIVEIRA, D. P. R. Holding, administração corporativa e unidade estratégica de negócio: uma abordagem prática. 2. ed. São Paulo: Atlas, 1999.

PORTER, M. E. Estratégia Competitiva: técnicas para análise de indústrias e da concorrência. 17. ed. Rio de Janeiro: Campus, 1986.

American's Green Strategy. Scientific American, v. 264, n.4, p. 168-176, abr. 1991.

PORTER, M. E.; VAN DER LINDE, C. Toward a new conception of the environmentcompetitiveness relationship. Journal of Economic Perspectives, v. 9, n. 4, p. 97-118, 1995a. 
. Green and Competitive: Ending the Stalemate. Harvard Business Review, v.73, n. 5, p.120-134, set/out. 1995b.

SINMETAL - SINDICATO DAS INDÚSTRIAS METALÚRGICAS, MECÂNICAS E DE MATERIAL ELÉTRICO E ELETRÔNICO DO ESTADO DO RIO GRANDE DO SUL. Piso salarial metalúrgico para empresas com até 30 empregados. Disponível em:

<www.sinmetal.org.br/info84/tabtrib.htm.24k>. Acesso em: 29 mar. 2004.

SINCLAIR-DESGAGNÉ, B. Remarks on environmental regulation firm behavior and innovation. Série cientifique 99S-20, Centre interuniversitaire de recherche en analyse des organisations (CIRANO), Montreal, 1999.

Recebido em: 01/01/2006

Aprovado para publicação: 02/02/2008 